\title{
Inhibitory effect of botanicals and bioagents against Ustilaginoidea virens (Cooke) Takah. causing false smut of rice
}

\author{
Manish Kumar Maurya , S.K. Singh, Vikash Kumar Yadav, S.N. Rahul and S.P. Vishwakarma
}

Department of Plant Pathology, Acharya Narendra Deva University of Agriculture and Technology, Kumarganj, Ayodhya-224229, U.P., India

\begin{tabular}{l} 
Article Info \\
\hline Article history \\
Received 28 June 2021 \\
Revised 14 August 2021 \\
Accepted 16 August 2021 \\
Published Online 30 December 2021
\end{tabular}

Keywords

Rice

False smut

Botanicals

Bioagents

Ustilaginoidea virens (Cooke) Takah.

\begin{abstract}
Ustilaginoidea virens (Cooke) Takah. causing false smut of rice is a destructive disease which causes an economic yield loss ranges from $0.2-49 \%$. The present study is carried out to check inhibitory effect of botanicals and bioagents against $U$. virens. Among botanicals, neem oil at both concentration, i.e., 5 per cent and 10 per cent was found highly effective and inhibit the growth by $66.97 \%$ and $70.14 \%$, respectively followed by onion $(62.89 \%, 67.64 \%)$, garlic $(58.82 \%, 64.25 \%)$, ginger $(55.88 \%, 63.57 \%)$ and tulsi $(46.40 \%, 54.98 \%)$. Among bioagents, maximum inhibition $(53.55 \%)$ was observed in Bacillus subtilis followed by Pseudomonas fluorescence (41.87\%), Trichoderma viride (40.35\%) and Trichoderma harzianum $(36.29 \%)$ in in vitro condition.
\end{abstract}

\section{Introduction}

Rice (Oryza sativa L.) being the most staple cereal food crop, grown in India, providing one third of calories requirement for more than 70 per cent of Indian population. More than 90 per cent of world's rice is grown and consumed in Asia, known as rice bowl of the world. To focus attention on the importance of rice in global food security and necessity into increased rice production and productivity, United Nation General Assembly in 2002, declared to celebrate the year 2004 as "International year of rice.

In India, it is cultivated in an area of 43.77 Mha with a production of 169.14 Mt and has an average productivity $3.86 \mathrm{t} / \mathrm{ha}$ (Anonymous, 2019). The major rice producing states are West Bengal, Punjab, Uttar Pradesh, Andhra Pradesh, Bihar and Tamil Nadu. In Uttar Pradesh, it is cultivated in an area of 5.81 Mha with production of 19.91 Mt and average productivity 3.42 t/ha (Anonymous, 2019).

Rice crop is affected by number of biotic and abiotic factors. Among biotic factors, diseases caused by fungi, bacteria, virus and others are the major one. False smut is one of the most calamitous fungal diseases of rice and its occurrence is reported from every corner of the world wherever rice is growing (Ladhalakshmi et al., 2018). Initially, the disease was of minor importance and commonly known as "Welcome/Lakshmi disease" because the disease was considered as an indicator of vigorous crop resulting into good harvest but due to continuous use of high dose of nitrogenous fertilizer extensively,

Corresponding author: Mr. Manish Kumar Maurya Department of Plant Pathology, Acharya Narendra Deva University of Agriculture and Technology, Kumarganj, Ayodhya-224229, Uttar Pradesh,India

E-mail: mkmndu@gmail.com

Tel.: +91-8574847592

Copyright (C) 2021 Ukaaz Publications. All rights reserved.

Email: ukaaz@yahoo.com; Website: www.ukaazpublications.com cultivation of hybrid cultivars and climate change, the disease becomes major one (Jehua et al., 2019). The disease was first reported from Tirunelveli district of Tamil Nadu state of India (Cooke, 1878). The False smut pathogen $U$. virens infect the plant during flowering stage where an individual healthy grain converts firstly into whitish, yellowish orange to green velvety spores which later turns into greenish black in colour (Baite et al., 2014).

In Uttar Pradesh, a yield loss was recorded ranges from 5-85 per cent (Singh et al., 2014). Continuous use of fungicides has resulted in accumulation of toxic compounds which is hazardous to humans, animals and environment and also build-up resistance in the pathogens. So, botanicals and bioagents are the best alternative and economical way to manage the disease. Management of diseases and pests by the use of plant-based products was practiced over time until synthetic pesticides were developed (Mahmood et al., 2016). Various researchers reported different effective botanicals from timeto-time. Neem and garlic was found effective as reported by Mahmud et al. (2017). Different bioagents are normally dominant components of the soil microflora in extensively varying habitats and are very effective against the $U$. virens (XiaoLe et al., 2011; Kannahi et al., 2016; Nath and Das, 2020). Therefore, the present investigation was carried out to know the appropriate and effective botanicals and bioagents against $U$. virens in vitro.

\section{Materials and Methods}

The experiments were conducted in the laboratory of Department of Plant Pathology, Acharya Narendra Deva University of Agriculture and Technology, Kumarganj, Ayodhya, U.P. during 2020-21.

\subsection{Isolation of pathogen}

Panicles infected with false smut were collected from the NSP-6 farm of the University. The smut balls were brought to the laboratory 
and isolates them on a PDA (Potato Dextrose Agar) medium as described by Ladhalakshmi et al., 2012. The smut balls were thoroughly washed repeatedly in tap water. Surface sterilized in a sodium hypochlorite $\left(1 \% \mathrm{NaOCl}_{2}\right)$ solution for $30 \mathrm{sec}$, followed by three times rinsing in sterilized distilled water. The false smut balls were cut into two halves, the inner layer containing spores was then streaked on PSA medium which was supplemented with 100 ppm streptomycin to avoid bacterial contamination. The inoculated Petriplates were incubated in a BOD incubator at $25 \pm 1^{\circ} \mathrm{C}$. After 10 days of incubation, the mycelial growth of $U$. virens was observed. The isolates were purified by hyphal tip method. The culture obtained by this method was maintained on PSA slants and Petri plates.

\subsection{Preparation of plant extracts}

The plant parts were collected from main Experiment Station of Vegetable Science of the University. The plant parts were washed with tap water followed by sterilized water. In case of water extract of botanicals, $100 \mathrm{~g}$ of botanicals were crushed in $100 \mathrm{ml}$ of water separately, grinded with pestle and mortar in water in in vitro condition for $10 \mathrm{~min}$. Then, the extracted juice were sieved and taken in conical flask and stored at $4^{\circ} \mathrm{C}$.

\subsection{Evaluation of botanicals against $U$. virens}

Inhibitory effect of five botanical extracts (Table 1) were tested at two concentrations, i.e., 5 per cent and 10 per cent against the mycelial growth of $U$. virens. Required quantity of each treatment was incorporated in $100 \mathrm{ml}$ PDA at luke warm stage and mixed thoroughly by sacking, prior to pouring into Petri plates. After pouring of PDA in Petri plates, the medium was allowed to solidify and these plates were centrally inoculated with the $6 \mathrm{~mm}$ diameter disc of $U$. virens at the centre of the Petri plate. The disc is cut by sterilized cork borer taken from the edge of vigorously grown 10 days old culture. Control was used as such without treatment in the medium. Four replications of each treatment incubated at $26 \pm$ $2^{\circ} \mathrm{C}$ for growth of the pathogen. The efficacy of various chemicals was observed by measuring mycelial growth of the fungus in millimeters $(\mathrm{mm})$. The mycelia growth was recorded after 10 days of incubation.

Table 1: List of botanicals, their scientific name, family and plant parts used

\begin{tabular}{|c|l|l|l|l|}
\hline S.No. & Botanicals & Scientific name & Family & Plant parts used \\
\hline $\mathbf{1}$ & Garlic & Allium sativum & Amaryllidaceae & Clove \\
\hline $\mathbf{2}$ & Ginger & Zingiber officinalis & Zingiberaceae & Rhizome \\
\hline $\mathbf{3}$ & Neem oil & Azadirachta indica & Neliaceae & Oil \\
\hline $\mathbf{4}$ & Onion & Allium cepa & Liliaceae & Bulb \\
\hline $\mathbf{5}$ & Tulsi & Ocimum sanctum & Lamiaceae & Leaf \\
\hline
\end{tabular}

Table 2: Efficacy of botanicals (after 10 day) at different concentration against $U$. virens causing false smut of rice

\begin{tabular}{|c|c|c|c|c|c|}
\hline \multirow[t]{2}{*}{ S.No. } & \multirow[t]{2}{*}{ Botanicals } & Radial growth (mm) & \multirow[t]{2}{*}{ Inhibition \% } & Radial growth (mm) & \multirow[t]{2}{*}{ Inhibition \% } \\
\hline & & Conc. $(5 \%)$ & & Conc. $(10 \%)$ & \\
\hline $\mathrm{T}_{1}$ & Garlic (Allium sativum) & 18.2 & 58.82 & 15.8 & 64.25 \\
\hline $\mathrm{T}_{2}$ & Ginger (Zingiber officinalis) & 19.5 & 55.88 & 16.1 & 63.57 \\
\hline $\mathrm{T}_{3}$ & Neem oil (Azadirachta indica) & 14.6 & 66.97 & 13.2 & 70.14 \\
\hline $\mathrm{T}_{4}$ & Onion (Allium cepa) & 16.4 & 62.89 & 14.3 & 67.64 \\
\hline $\mathrm{T}_{5}$ & Tulsi (Ocimum sanctum) & 23.6 & 46.60 & 19.9 & 54.98 \\
\hline $\mathrm{T}_{6}$ & Control & 44.2 & - & 44.2 & - \\
\hline & $\begin{array}{l}\mathrm{CD}(p=0.01) \\
\mathrm{CV}\end{array}$ & $\begin{array}{l}1.17 \\
1.61 \\
\end{array}$ & & $\begin{array}{l}1.03 \\
1.51 \\
\end{array}$ & \\
\hline
\end{tabular}

\subsection{Evaluation of bioagents against $U$. virens}

All the bioagents isolates were collected from the Department of Plant Pathology, ANDUAT, Ayodhya to evaluate their efficacy against the U. virens, viz., Trichoderma viride, Trichoderma harzianum, Pseudomonas fluorescence and Bacillus subtilis through dual culture technique. The $6 \mathrm{~mm}$ disc of $U$. virens and bioagents were placed at corresponding to each other in a single Petri plate. The efficacy of various treatments was assessed by measuring the myelial growth of the fungus after 10 days of incubation.

The per cent inhibition of mycelial growth was calculated by using the formula (Mckinney, 1923):
Inhibition per cent $(\mathrm{I})=\frac{\mathrm{C}-\mathrm{T}}{\mathrm{C}} \times 100$ where,

$$
\begin{aligned}
\mathrm{I} & =\text { Inhibition per cent } \\
\mathrm{C} & =\text { Colony diameter in control } \\
\mathrm{T} & =\text { Colony diameter in treatment }
\end{aligned}
$$

\subsection{Statistical analysis}

The data recorded on radial growth were statistically analyzed using completely randomized block design (Web Agri Stat Package 1.0). 


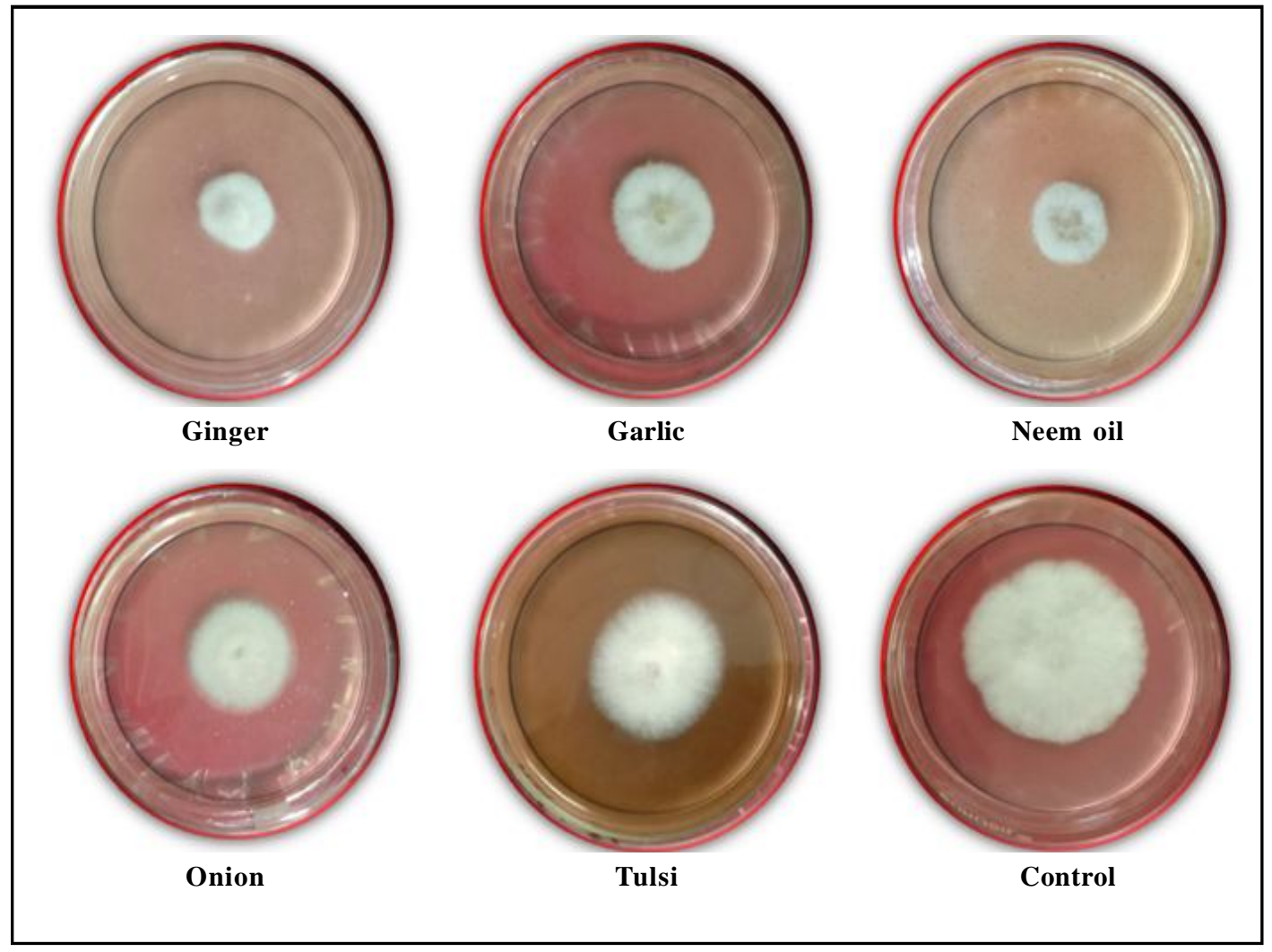

Plate 1: Efficacy of botanicals at $5 \%$ on the growth of $U$. virens (after 10 days).

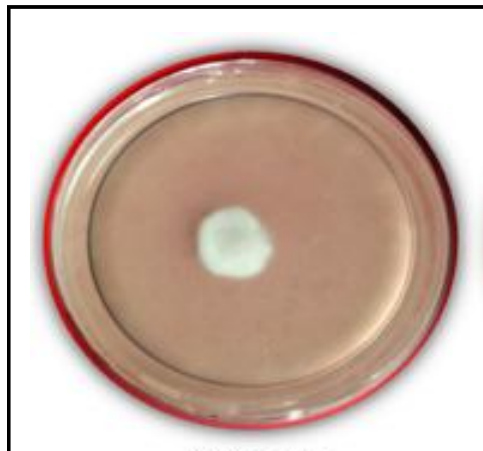

Ginger
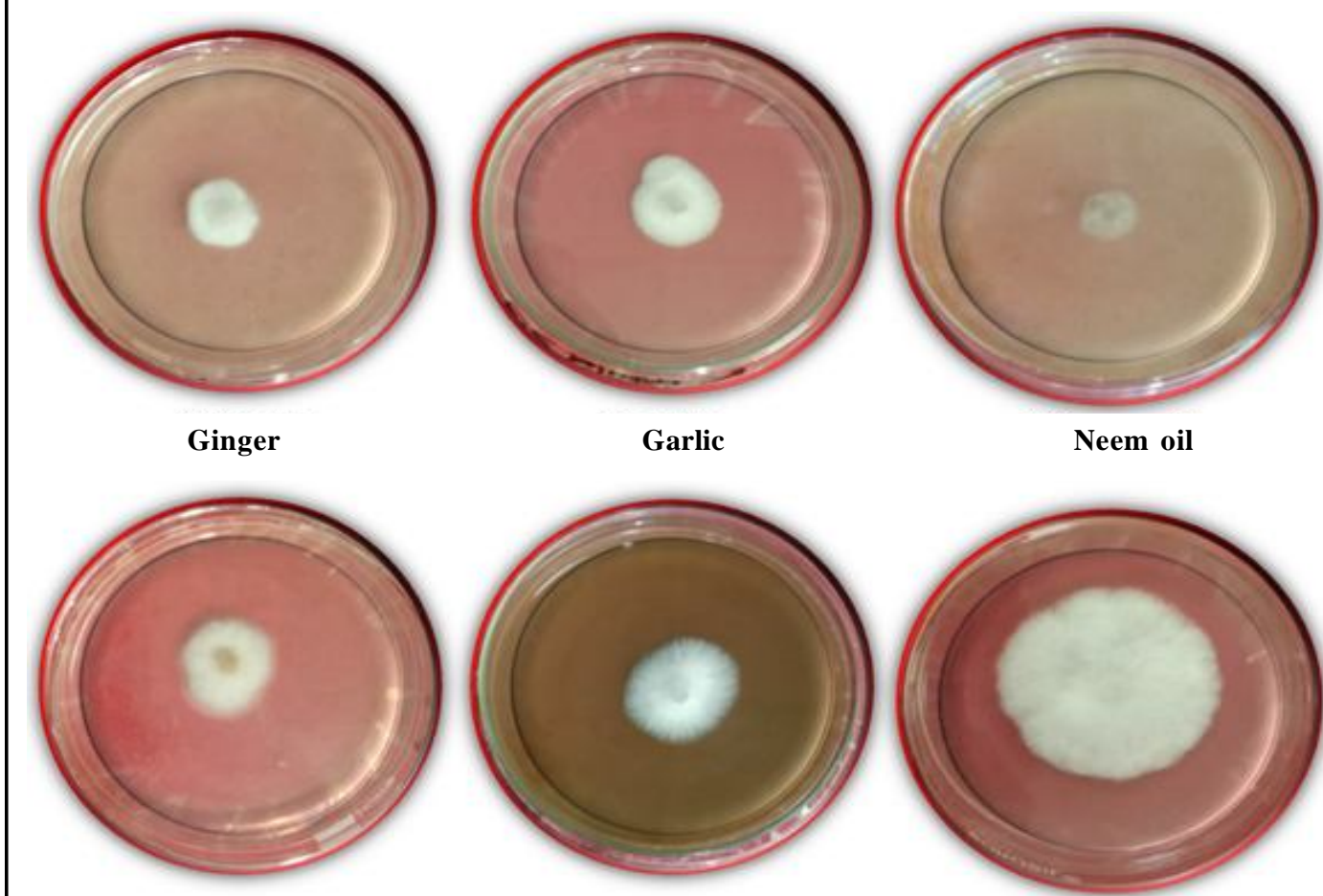

Onion
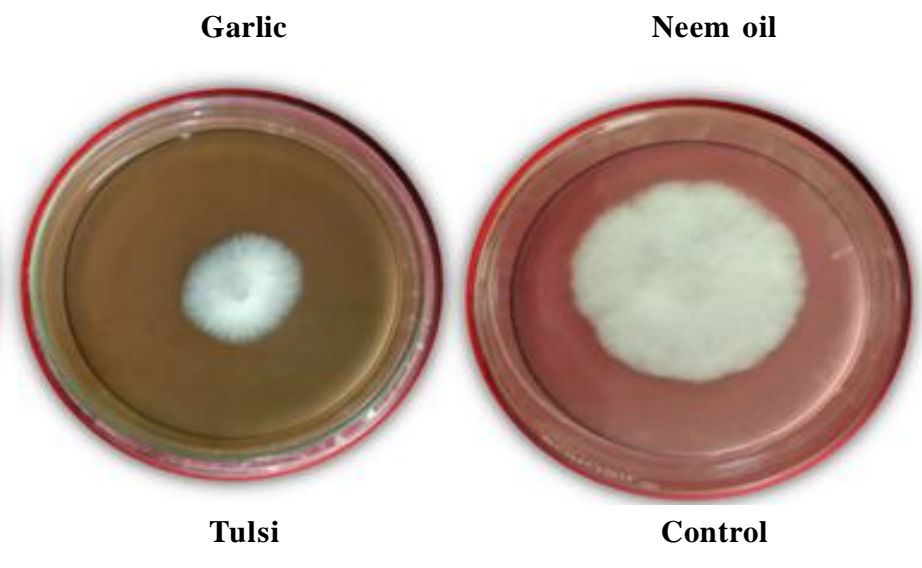

Plate 2: Efficacy of botanicals at $10 \%$ on the growth of $U$. virens (after 10 days) 


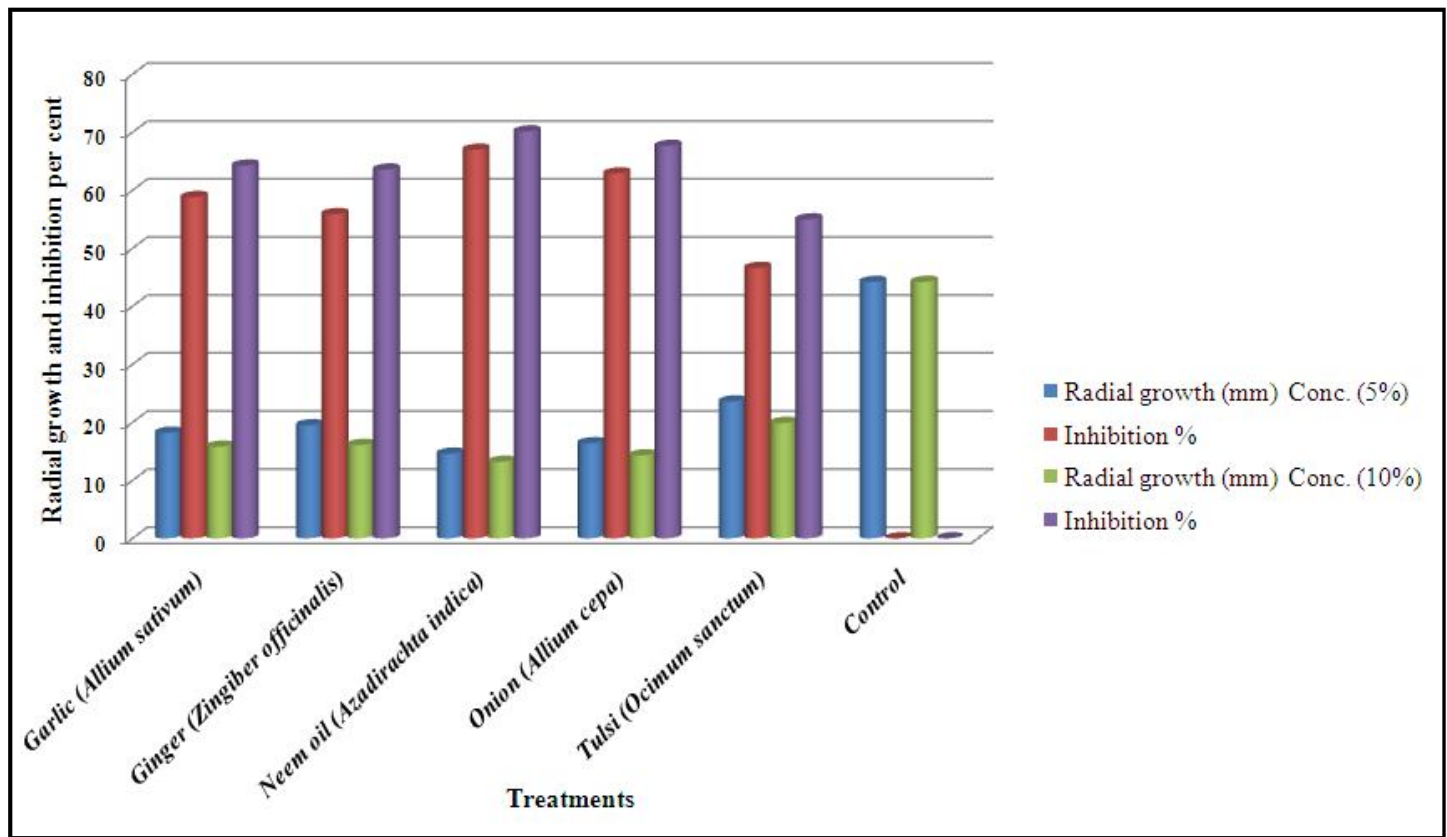

Figure 1: Efficacy of botanicals (after 10 day) at different concentrations against $U$. virens.

Table 3: Efficacy of bioagents (after 10 days) against $U$. virens causing false smut of rice.

\begin{tabular}{|l|l|c|c|}
\hline S. No. & Bioagents & $\begin{array}{c}\text { Colony diameter of } \\
\text { pathogen }(\mathbf{m m})\end{array}$ & Inhibition \% \\
\hline $\mathrm{T}_{1}$ & Trichoderma viride & 23.5 & 40.35 \\
\hline $\mathrm{T}_{2}$ & Trichoderma harzianum & 25.1 & 36.29 \\
\hline $\mathrm{T}_{3}$ & Pseudomonas fluorescence & 22.9 & 41.87 \\
\hline $\mathrm{T}_{4}$ & Bacillus subtilis & 18.3 & 53.55 \\
\hline $\mathrm{T}_{5}$ & Control & 39.4 & - \\
\hline & CD $(\boldsymbol{p}=\mathbf{0 . 0 1})$ & $\mathbf{0 . 6 5}$ & \\
\hline & $\mathbf{C V}$ & $\mathbf{0 . 7 1}$ & \\
\hline
\end{tabular}

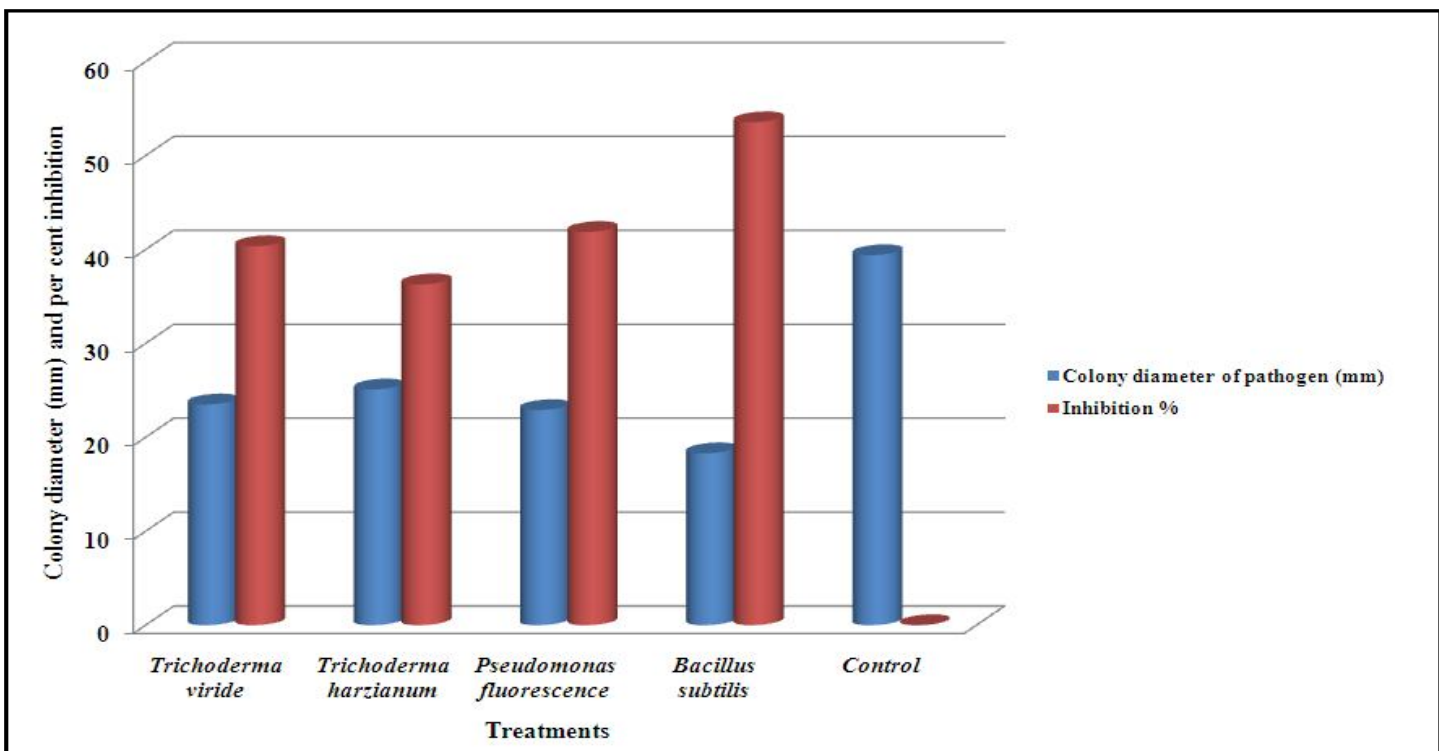

Figure 2: Efficacy of bioagents (after 10 days) against $U$. virens causing false smut of rice. 


\section{Results}

3.1 Effect of botanicals at different concentration on the mycelial growth of $U$. virens

Five botanicals were tested in present study under lab condition through food poison technique in 5 per cent and 10 per cent concentrations. Data were recorded 10 day after incubation on the basis of effect of botanicals on the mycelial growth $(\mathrm{mm})$ of the pathogen is presented in Table 2 .

\subsubsection{Effect of botanicals on the mycelia growth at 5 per cent concentration}

The results presented in Table 2, Figure 1 and Plate 1 revealed that the minimum $U$. virens growth $(14.6 \mathrm{~mm})$ was observed in neem. Neem is found at par with onion having radial growth $16.4 \mathrm{~mm}$, followed by garlic $(18.2 \mathrm{~mm})$, ginger $(19.5 \mathrm{~mm})$ and tulsi $(23.6 \mathrm{~mm})$. The maximum $44.2 \mathrm{~mm}$ mycelial growth was observed in control.

\subsubsection{Effect of botanicals on the mycelia growth at 10 per cent concentration}

The results presented in Table 2, Figure 1 and Figure 2 revealed that the minimum $U$. virens growth $(13.2 \mathrm{~mm})$ was observed in neem. Neem is found at par with onion having radial growth $14.3 \mathrm{~mm}$, followed by garlic $(15.8 \mathrm{~mm})$, ginger $(16.1 \mathrm{~mm})$ and tulsi $(19.9 \mathrm{~mm})$. $\mathrm{T}_{4}$ was found at par with $\mathrm{T}_{2}$. The maximum $44.2 \mathrm{~mm}$ mycelial growth was observed in control.

3.2 Effect of botanicals at different concentration on the growth inhibition of $U$. virens after 10 days

All the botanicals significantly inhibit the mycelial growth of $U$. virens. Neem oil at 5 per cent and 10 per cent was found most effective and inhibit the growth by $66.97 \%$ and $70.14 \%$, respectively followed by onion $(62.89 \%, 67.64 \%)$, garlic $(58.82 \%, 64.25 \%)$, ginger $(55.88 \%, 63.57 \%)$ and tulsi $(46.40 \%, 54.98 \%)$.

3.3 Effect of bioagents on the mycelial growth of $U$. virens through dual culture technique.

Inhibitory effects of different bioagents were evaluated through dual culture technique. The results were recorded after 10 days of incubation and presented in Table 3 and Figure 2. It revealed that the minimum radial growth was observed in Bacillus subtilis $(18.3 \mathrm{~mm})$ followed by Pseudomonas fluorescence $(22.9 \mathrm{~mm})$, Trichoderma viride $(23.5 \mathrm{~mm})$ and Trichoderma harzianum $(25.1 \mathrm{~mm})$. Pseudomonas fluorescence and Trichoderma viride were found at par to each other. All the treatments were found significantly superior over the control.

All the bioagents notably inhibit the mycelia growth of $U$. virens. Maximum per cent inhibition 53.55 per cent was observed in Bacillus subtilis followed by Pseudomonas fluorescence 41.87 per cent, Trichoderma viride 40.35 per cent and Trichoderma harzianum 36.29 per cent.

\section{Discussion}

Uses of botanicals and bioagents are the best alternative of fungicides for the management of diseases due to its eco-friendly nature and also economically. Many plant extracts gives excellent result against phytopathogens. Here, study identified that neem oil, onion bulb extract and garlic clove extract was found highly effective against the disease. The results found was well supported by Mahmud et al. (2017) as he also found that neem and garlic was found effective against $U$. virens. Integration of botanicals in present agriculture system is necessary as it possess many benefit to the farmers including food safety, reduced disease levels, improve food quality which catch higher marketable price (Lengai et al., 2020). It possesses many antimicrobial metabolites which help inhibiting the mycelial growth of pathogen.

All the bioagents significantly inhibit the growth of $U$. virens. Maximum per cent inhibition was observed in Bacillus subtilis (53.55), followed by Pseudomonas fluorescence (41.87), Trichoderma viride (40.35) and Trichoderma harzianum (36.29). The results were well supported by XiaoLe et al. (2011); Nath and Das (2020) found Bacillus sp. most effective. Kannahi et al. (2016) studied the antagonistic potential of four isolates of Trichoderma spp., viz., T. viride, T. harzianum, T. reesei and T. virens obtained from rhizosphere of rice under in vitro condition and reported that all the Trichoderma isolates are highly effective against $U$. virens. The different species of Trichoderma was also found effective and maximum inhibit the growth (Kumar et al., 2014; Mahmud et al., 2017). The antagonistic fungus or bacteria affected or inhibited a plant pathogen by the action of mycoparasitism, antibiosis, competition for nutrients and space. The antagonists produces different extracellular enzymes like glucanase, chitinase, etc., to mortify the mycelia growth of pathogen (Kohl et al., 2019). It could be used for sustainable management of disease without harming the environment.

\section{Conclusion}

The present study identified various plant extracts (garlic, ginger, neem oil, onion, tulsi) and bioagents (Bacillus subtilis, Pseudomonas fluorescence, Trichoderma viride and Trichoderma harzianum) against the pathogen $U$. virens at different concentration. Neem oil was found highly effective followed by onion and garlic. Maximum per cent inhibition was observed in Bacillus subtilis followed by Pseudomonas fluorescence, Trichoderma viride and Trichoderma harzianum. All the plant extracts and bioagents evaluated significantly control the disease. So, they can be used to manage the disease under natural field condition. The future strategy required to identify plant or bioagents with antimicrobial potential and made the formulation from them with better shelf life and utilize them for eco-friendly and sustainable management of the disease without harming the environment.

\section{Acknowledgements}

The first author is grateful to Department of Science and Technology, Ministry of Science and Technology, Govt. of India, New Delhi, for providing INSPIRE fellowship during Ph.D. The authors also acknowledge the Director Research, ANDUAT, Ayodhya for providing all facilities during this study.

\section{Conflict of interest}

The authors declare no conflict of interest related to this article. 


\section{References}

Baite, M.S.; Sharma, R.K.; Devi, T.P.; Sharma, P. and Kamil, D. (2014) Morphological and molecular characterization of Ustilaginoidea virens isolates causing false smut of rice in India. Indian Phytopath., 67(3):222-227.

Cooke, M.C. (1878). Some extra-European fungi. Grevillea, 7:13-15.

Jehua, Q.; Shuai, M.; Yizhen, D.; Shiwen, H. and Yanjun, K. (2019). Ustilaginoidea virens: A fungus infects rice flower and threats world rice production. Rice Sci., 26(4):199-206. http://dx.doi.org/10.1016/j.rsci. 2018. 10.007 .

Kannahi, M.; Dhivya, S. and Senthilkumar, R. (2016). Biological control on rice false smut disease using Trichoderma species. Intl. J. Pure App. Bio. sci., 4(2):311-316. http://dx.doi.org/10.18782/2320-7051. 2237.

Köhl, J.; Kolnaar, R. and Ravensberg, W.J. (2019). Mode of action of microbial biological control agents against plant diseases: Relevance beyond efficacy. Front. Pl. Sci., 10:845. http://dx.doi.org/10.3389/fpls. 2019.00845

Kumar,A.; Sahu, T.K.; Bhalla, A. and Solani, S. (2014). Influence of Trichoderma sp. against Ustilaginoidea virens inciting false smut of rice. Environ. Ecol., 32(1):163-168.

Ladhalakshmi, D.; Laha, G.S.; Singh, R.; Karthikeyan, A.; Mangrauthia, S.K.; Sundaram, R.M.; Thukkaiyannan, P. and Viraktamath, B.C. (2012). Isolation and characterization of Ustilaginoidea virens and survey of false smut disease of rice in India. Phytoparasitica, 40:171-176. https:/ /doi.org/10.1007/s12600-011-0214-0.

Ladhalakshmi, D.; Madamsetty, S.P.; Vellaichamy, P.; Donempudi, K.; Banda, S.; Singh, R.; Prasad, V.; Lore, J.S.; Jain, J.; Mariappan, S. and Laha, G.S. (2018).
Geographic distribution of false smut disease of rice in India and efficacy of selected fungicides for its management. Intl. J. Pest Man., 65(2):177-185. https://doi.org/10.1080/09670874. 2018. 1494865 .

Lengai, G.M.W.; Muthomi, J.W. and Mbega, E.R. (2020). Phytochemical activity and role of botanical pesticides in pest management for sustanaible agricultural crop production. Scientific African, 7:e00239. https:// doi.org/10.1016/j.sciaf.2019.e00239.

Mahmud, H.; Hossain, I. and Ahmad, M.U. (2017). In vitro tests to determine the efficacy of plant extracts, BAU-Biofungicide and Fungicides on the Inhibitory Effects on Some Important Rice Pathogen. Curr. Res. J. Biol. Sci., 9(2):36-43. https://doi.org/10.19026/crjbs.9.5300.

Mahmood, I.; Imadi, S.R.; Shazadi, K.; Gul, A. and Hakeem, K.R. (2016). Effects of pesticides on environment. Pl. Soil Microbes, pp:253-269.

McKinney, H.H. (1923). A new system of grading plant diseases. J. Agric. Res., 26:195-218.

Nath, H.K.D. and Das, B.C. (2020). Evaluation of fungicides and bioformulation against Ustilaginoidea virens causing rice false smut disease. Intl. J. Curr. Microbiol. App. Sci., 9(11):3165-3170. https:/ /doi.org/10.20546/ijcmas.2020.911.381.

Singh, S.; Lal, A.A.; Simon, S.; Singh, A.; Yaduman, R.; Kamaluddeen and David, A.A. (2014). Survey of false smut (Ustilaginoidea virens) of rice (Oryza sativa L.) in some selected districts of Uttar Pradesh. The Bioscan., 9(1):389-392.

XiaoLe, Y.; Zhiyi, C.; YongFeng, L.; YouZhou, L.; XiaoYu, W.; ChuPing, L.; Junjei, Y. and YaFeng, N. (2011). Screening and evaluation of antagonistic bacteria against rice false smut. Jiangsu J. Agril. Sci., 27(5):983-989. 